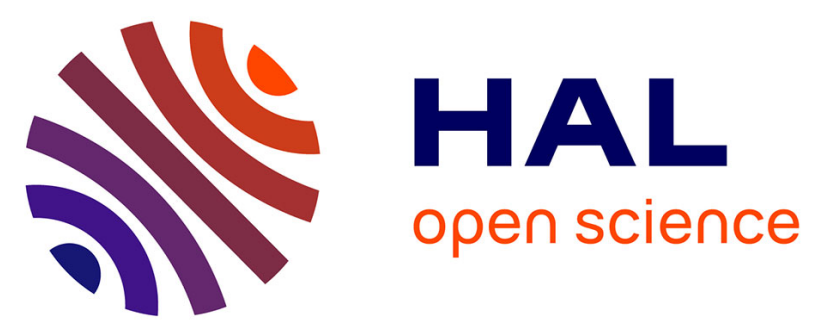

\title{
Lean body weight is the best scale for venous thromboprophylaxis algorithm in severely obese patients undergoing bariatric surgery
}

Benedicte Gaborit, Pierre-Antoine Moulin, Thierry Bege, Sandrine Boullu, Clara Vincentelli, Olivier Emungania, Pierre-Emmanuel Morange, Stephane Berdah, Joe-Elie Salem, Anne Dutour, et al.

\section{To cite this version:}

Benedicte Gaborit, Pierre-Antoine Moulin, Thierry Bege, Sandrine Boullu, Clara Vincentelli, et al.. Lean body weight is the best scale for venous thromboprophylaxis algorithm in severely obese patients undergoing bariatric surgery. Pharmacological Research, 2018, 131, pp.211-217. 10.1016/j.phrs.2018.02.012 . hal-02091330

\section{HAL Id: hal-02091330 \\ https://hal-amu.archives-ouvertes.fr/hal-02091330}

Submitted on 11 Dec 2019

HAL is a multi-disciplinary open access archive for the deposit and dissemination of scientific research documents, whether they are published or not. The documents may come from teaching and research institutions in France or abroad, or from public or private research centers.
L'archive ouverte pluridisciplinaire HAL, est destinée au dépôt et à la diffusion de documents scientifiques de niveau recherche, publiés ou non, émanant des établissements d'enseignement et de recherche français ou étrangers, des laboratoires publics ou privés. 


\title{
Lean body weight is the best scale for venous thromboprophylaxis algorithm in severely obese patients undergoing bariatric surgery
}

\author{
Bénédicte Gaborit ${ }^{\mathrm{a}, \mathrm{b}, \mathrm{c}, *}$, Pierre-Antoine Moulin ${ }^{\mathrm{d}}$, Thierry Bege ${ }^{\mathrm{a}, \mathrm{e}}$, Sandrine Boullu ${ }^{\mathrm{a}, \mathrm{b}}$, \\ Clara Vincentelli ${ }^{a, b, c}$, Olivier Emungania ${ }^{a, e}$, Pierre-Emmanuel Morange ${ }^{\mathrm{c}, \mathrm{d}}$, \\ Stéphane Berdah ${ }^{\mathrm{a}, \mathrm{e}}$, Joe-Elie Salem ${ }^{\mathrm{f}, \mathrm{g}}$, Anne Dutour ${ }^{\mathrm{a}, \mathrm{b}, \mathrm{c}}$, Corinne Frere ${ }^{\mathrm{h}}$ \\ a Centre Spécialisé de l'obésité (CSO) PACA Ouest, France \\ ${ }^{\mathrm{b}}$ Endocrinology, Metabolic Diseases and Nutrition Department, Pole ENDO, Assistance Publique - Hôpitaux de Marseille, Aix-Marseille Université, \\ Marseille, France \\ c Aix Marseille Univ, INSERM, UMR1263, INRA, C2VN, Marseille, France \\ ${ }^{\mathrm{d}}$ Hematology Department, Timone Hospital, Assistance Publique - Hôpitaux de Marseille, Aix-Marseille Université, Marseille, France \\ e Digestive Surgery Department, Pole ADOU North Hospital, Assistance Publique - Hôpitaux de Marseille, Aix-Marseille Université, Marseille, France \\ f Department of Pharmacology and CIC-1421, Assistance Publique - Hôpitaux de Paris, Pitié-Salpêtrière Hospital, INSERM, CIC-1421 and UMR ICAN 1166, \\ Paris, France \\ ' Sorbonne Universités, UPMC Univ Paris 06, Faculty of Medicine, Paris, France \\ h INSERM, UMR_S 1166; Sorbonne Universités, UPMC Université Paris 06, UMR_S 1166; Institute of Cardiometabolism and Nutrition, ICAN; Assistance \\ Publique Hôpitaux de Paris, Pitié-Salpêtrière Hospital, Haematology Department, F-75013 Paris, France \\ * Corresponding author at: Aix Marseille Univ, INSERM, UMR1263, INRA, C2VN, \\ Marseille, France.
}

E-mail address: benedicte.gaborit@ap-hm.fr (B. Gaborit).

Keywords:

Severe obesity

Venous thromboembolism

Low-molecular-weight heparin

Lean body weight

Glomerular filtration rate

Anti-Xa activity

\begin{abstract}
Severely obese patients undergoing bariatric surgery (BS) are at increased risk for venous thromboembolism (VTE). How standard low molecular weight heparin (LMWH) regimen should be adapted to provide both sufficient efficacy and safety in this setting is unclear. We aimed to compare the influence of four body size descriptors (BSD) on peak anti-Xa levels in BS obese patients receiving LMWH fixed doses to identify which one had the greatest impact. One hundred and thirteen BS obese patients [median body mass index (BMI), $43.3 \mathrm{~kg} / \mathrm{m}^{2}$ (IQR, 40.6-48.7 kg/m²)] receiving subcutaneous dalteparin 5000 IU twice daily were included in this prospective monocenter study. Peak steady-state anti-Xa levels were measured peri-operatively following thromboprophylaxis initiation. Only $48 \%$ of patients achieved target anti-Xa levels $(0.2-0.5 \mathrm{IU} / \mathrm{ml})$. In univariate analysis, age, gender, total body-weight (TBW), lean body-weight (LBW), ideal body-weight (IBW), BMI and estimated glomerural filtration rate (eGFR) were associated with anti-Xa levels. The strongest negative association was observed with $\mathrm{LBW}(\mathrm{r}=-0.56, \mathrm{p}<.0001)$. Receiver operating characteristic curves indicated that among BSD, LBW (cut-off $>55.8 \mathrm{~kg}$ ) had the highest sensitivity (73\%) and specificity (69\%) to predict sub-prophylactic anti-Xa levels. In multivariate analysis, LBW and eGFR remained associated with anti-Xa levels $(\beta=-0.47 \pm 0.08, p<.0001$ and $\beta=-0.19 \pm 0.08$; $\mathrm{p}=.02$, respectively). In BS morbidly obese patients receiving LMWH for thromboprophylaxis after BS, LBW and eGFR are the main determinants of anti-Xa level, and could be proposed in LMWH-based thromboprophylaxis dosing algorithms. The efficacy of a LBW-scale based dosing algorithm for optimal VTE prevention deserves further prospective randomized trials.
\end{abstract}

\section{Introduction}

Severe obese patients undergoing bariatric surgery (BS) are at increased risk for venous thromboembolism (VTE) [1-3] and VTE- related mortality [4-6]. Efficient thromboprophylaxis is thus highly warranted.

Given their pharmacokinetic profile, their better bioavailability, and their more predictable anticoagulant effect, standard fixed dosing of low molecular weight heparins (LMWH), without the need for monitoring or adjusting regimens, have become the therapy of choice for VTE prophylaxis in both medical and surgical setting. However, in severe obese patients, changes in body composition, renal glomerular filtration, volume of distribution, cardiac output 
and metabolic processes may considerably affect drug response, resulting in either under or overdosing [7].

Scarce pharmacodynamic studies using LMWH for VTE prophylaxis in severely obese patients found a negative correlation between plasma anti-Xa activity and body weight, suggesting that higher than standard LMWH fixed dosing would be required in these patients [8-10]. Moreover, several observational studies challenged the notion that LMWH standard fixed dosing results in adequate prophylaxis in this specific population. Indeed, prophylactic anti-Xa levels were not achieved with standard fixed LMWH dosing in most cases [11-15], whereas the proportion of patients achieving appropriate anti-Xa levels increased with higher than standard fixed dosing [11-14]. However, increasing the dosing in parallel with body weight without gate seems hazardous in severely obese patients. Consequently, current international guidelines do not mention whether LMWH dose should be adjusted, and to what extent [16-19].

In the lack of consensus regarding how adjusting LMWH dose in obese patients, different weight-scales have been proposed, such as total body weight (TBW) [20], and body mass index (BMI) [21,13]. It is noteworthy that a LMWH adapted regimen truly based on TBW could result in overdosing and increased bleeding risk, since LMWH have low lipophilic properties, and do not distribute into fat tissue, but remains in the vascular compartment. But given the paucity of data and the heterogeneity of obesity phenotypes, it remains unclear how LMWH regimen should be adapted to provide both sufficient efficacy and safety. Accordingly, the prophylactic dose of LMWH is often increased according to a weight-scale based dosing algorithm, but capped in severely obese patients, resulting in a fixed arbitrary dose for a heterogeneous group of patients.

In this prospective real life study, we aimed to compare the influence of four body size descriptors (BSD) on peak anti-Xa levels at steady-state in BS morbidly obese patients receiving a fixed double dose of dalteparin (5000 IU subcutaneously, twice daily) for VTE prevention, in order to identify which one has the greatest impact, and could further be explored for an adjusted LMWH dosing algorithm for achieving optimal VTE prevention in BS severely obese patients.

\section{Methods}

\subsection{Study design}

This prospective monocentric study (NCT03218514) was performed between July 2014 and March 2017 at the Digestive Surgery Unit of North Hospital (Marseille, France). Patients between 18 and 70 years old having a BMI $\geq 40 \mathrm{~kg} / \mathrm{m}^{2}$, or $\geq 35 \mathrm{~kg} / \mathrm{m}^{2}$ with at least one or more obesity-related co-morbidities including type 2 diabetes (T2DM), hypertension, obstructive sleep apnea (OSA), non-alcoholic fatty liver disease, severe osteoarthritis, dyslipidemia, gastrointestinal disorders, or heart disease, scheduled for sleeve gastrectomy (SG) or gastric bypass procedure (GBP) and agreeing to participate in the study were prospectively enrolled. Exclusion criteria included anticoagulant administration within $48 \mathrm{~h}$ preceding surgery, ongoing antiplatelet therapy, and pregnancy. LMWH were used according to the last French Society of Anaesthesia and Intensive Care Guidelines on thromboprophylaxis in BS [22]. Fixed-dose of dalteparin ( $5000 \mathrm{IU})$ were given subcutaneously twice daily for 14 days. The first dose was administered post-operatively, on the day of surgery (mean $6 \mathrm{~h}$ ). The present study protocol conformed to the ethical guidelines of the 1964 Declaration of Helsinki, and was approved by the human research committee of our institution. All patients gave an informed consent to participate in the study.

\subsection{Data collection}

Medical data including the type of BS performed, demographics, BMI, obesity-related co-morbidities, prior history of venous thromboembolism, prior history of autoimmune disease, prior history of malignancy, smoking status, total bed rest condition, and biological data were retrieved from the electronic patient files. T2DM was defined according to the WHO criteria (fasting plasma glucose $\geq 7.0 \mathrm{mmol} / \mathrm{l}(126 \mathrm{mg} / \mathrm{dl})$ or $2-\mathrm{h}$ plasma glucose $\geq 11.1 \mathrm{mmol} / 1$ $(200 \mathrm{mg} / \mathrm{dl}))$, and/or being on antidiabetic drugs. Hypertension was defined as a blood pressure of above $140 / 90 \mathrm{mmHg}$ and/or being on antihypertensive drugs. Dyslipidemia was defined as the use of statins and/or a raised total cholesterol level, LDL, or triglycerides above the 95th percentile according to the definition proposed by the American Heart Association [23]. Obstructive sleep apnea (OSA) was defined as OSA proven with formal sleep study. Lean body weight (LBW) was calculated according to the formula of Janmahasatian [24], ideal body weight (IBW) was calculated according to the formula of Devine [25], and estimated globular filtration rate (eGFR) was computed according to the formula of Modification of Diet in Renal Disease (MDRD) [26].

\subsection{Laboratory assessments}

Blood samples were collected in $3.2 \%$ buffered trisodium citrate tubes and twice centrifuged at $2500 \mathrm{~g}$ for $15 \mathrm{~min}$ at room temperature to obtain platelet-poor plasma. Plasma was aliquoted and stored at $-80^{\circ} \mathrm{C}$ until further analysis. Peak plasma levels of antiXa activity were determined $4 \mathrm{~h}$ after injection, at steady-state (at least day 2 after thromboprophylaxis initiation) using the chromogenic STA ${ }^{\circledR}$-Rotachrom ${ }^{\circledR}$ Heparin assay (Stago, Asnières, France) on a STA-R Evolution ${ }^{\circledR}$ analyzer (Stago, Asnières, France). Results were expressed as peak anti-Xa levels (IU/ml).

\subsection{Outcomes}

The primary outcome of the study was the proportion of patients whose peak plasma anti-Xa levels were not in the prophylactic ranges. The target range for prophylactic anti-Xa levels was defined as $0.2-0.5 \mathrm{IU} / \mathrm{ml}$ [26]. Peak anti-Xa levels below $0.2 \mathrm{IU} / \mathrm{ml}$ were defined as subprophylactic, and above $0.5 \mathrm{IU} / \mathrm{ml}$ as supraprophylactic. Subgroup analyses were conducted to determine whether anti-Xa levels differed based on total body weight (TBW), LBW, IBW or BMI stratum. TBW, LBW, IBW data were stratified into tertiles and BMI data were stratified into 3 groups (group $1, \mathrm{BMI}<40 \mathrm{~kg} / \mathrm{m}^{2}$; group $2,40 \leq \mathrm{BMI}<50 \mathrm{~kg} / \mathrm{m}^{2}$; group $\left.3, \mathrm{BMI} \geq 50 \mathrm{~kg} / \mathrm{m}^{2}\right)$. A 3 months follow-up was performed and symptomatic VTE as well as bleeding complications were recorded. Major bleeding complications were defined according to the International Society on Thrombosis and Haemostasis criteria [27]. All other bleeding events were defined as minor. The secondary outcome was the occurrence of both symptomatic VTE and major bleeding.

\subsection{Statistical analysis}

Statistical Analysis were performed using Graphpad Prism software v7.0 for windows (Graphpad Software Inc., San Diego, USA). Summary statistics were expressed as mean \pm standard deviation of the mean [SD], or median and inter-quartile range [IQR] as appropriate. The student $t$-test, the Mann-Whitney test and the Kriskal-Wallis test were used for between comparisons of quantitative data, as appropriate. The chi-square test was used for comparisons of categorical data. The spearman's or the Pearson's test were used to measure the strength of association between two variables, as appropriate. Multivariable analysis were performed by analysis of covariance (ANCOVA) (Xlstat software; Addinsoft ${ }^{\circledR}$, 
Table 1

Baseline patient characteristics.

\begin{tabular}{|c|c|c|c|c|}
\hline & All $(n=113)$ & Sleevegastrectomy $(\mathrm{n}=89)$ & Gastric by-pass $(\mathrm{n}=24)$ & $\mathrm{p}$ \\
\hline Age (years) & $42(34-53)$ & $42(34.5-53.5)$ & $42(31-53)$ & ns \\
\hline Gender (women), n(\%) & $89(78.8)$ & $65(73)$ & $23(95.8)$ & 0.0237 \\
\hline Total body weight (kg) & $119(108-135.5)$ & $117(108-135)$ & 123(106-139) & ns \\
\hline Excess weight $(\mathrm{kg})$ & 49.1(41.7-66.7) & $48.5(25.4-65.25)$ & $55.3(24.2-70.73)$ & ns \\
\hline Lean body weight (kg) & $56.4(51.9-64.9)$ & $57.1(52.5-71)$ & $55.2(51.6-61.8)$ & ns \\
\hline BMI $\left(\mathrm{kg} / \mathrm{m}^{2}\right)$ & $43.3(40.6-48.7)$ & $42.9(40.2-48.2)$ & $45.6(41.9-50.1)$ & ns \\
\hline \multicolumn{5}{|l|}{ Comorbidities } \\
\hline Diabetes, $\mathrm{n}(\%)$ & $24(21.2)$ & $20(22.5)$ & $4(16.7)$ & ns \\
\hline Hypertension, $\mathrm{n}(\%)$ & $38(33.6)$ & $32(36)$ & $6(25)$ & ns \\
\hline Dyslipidemia, n(\%) & $28(24.8)$ & $24(27)$ & $4(16.7)$ & ns \\
\hline Current Smokers, n(\%) & $8(7)$ & $6(6.7)$ & $2(8.3)$ & ns \\
\hline OSA, $n(\%)$ & $83(73.4)$ & $67(75.3)$ & $16(66.6)$ & ns \\
\hline Liver steatosis, n(\%) & $92(81.4)$ & $73(82)$ & $19(79.1)$ & ns \\
\hline Previous CAD, $n(\%)$ & $0(0)$ & $0(0)$ & $0(0)$ & ns \\
\hline Previous VTE, $\mathrm{n}(\%)$ & $2(1.8)$ & $2(2.3)$ & $0(0)$ & ns \\
\hline Prior history of malignancy & $7(6.2)$ & $5(5.6)$ & $2(8.3)$ & ns \\
\hline Prior history of autoimmune disease & $4(3.5)$ & $3(3.3)$ & $1(4.1)$ & ns \\
\hline Bedridden patient & $\mathbf{0}(\mathbf{0})$ & $\mathbf{0}(\mathbf{0})$ & $\mathbf{0}(\mathbf{0})$ & - \\
\hline Combined oral contraceptives, $\mathrm{n}(\%)$ & $13(11.5)$ & $12(13.4)$ & $1(4.2)$ & ns \\
\hline $\mathrm{eGFR}(\mathrm{ml} / \mathrm{min})$ & $97.0 \pm 19.7$ & $96.1 \pm 19.8$ & $100.7 \pm 19.5$ & ns \\
\hline Peak Anti Xa levels (IU/ml) & $0.2 \pm 0.1$ & $0.2 \pm 0.1$ & $0.2 \pm 0.1$ & ns \\
\hline
\end{tabular}

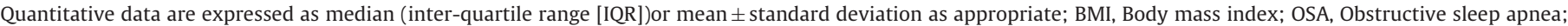

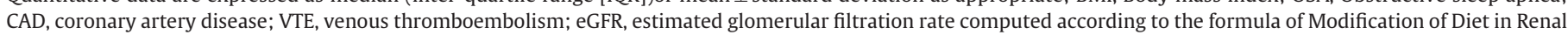
Disease (MDRD).

XLSTAT). Receiver operating characteristic (ROC) curves were constructed to assess the ability of the different BSD to predict subprophylactic anti-Xa levels. Statistical significance was accepted for $\mathrm{p}<.05$. The study had a power of $80 \%$ to detect a significant correlation (with $r \geq 0.26$, $\alpha$-risk 0.05 , Student approximation) between each covariables and peak anti-Xa levels.

\section{Results}

\subsection{Patient characteristics}

From July 2014 through March 2017, 118 consecutive patients were enrolled in the study. Two patients did not meet all inclusion criteria and 3 did not attend blood sampling. Finally, 113 patients were included in our prospective cohort. Baseline patient's characteristics are depicted in Table 1 . Most of patients $(n=89,78.7 \%)$ had a SG, while 24 patients $(21.3 \%$ ) underwent a GBP. All surgeries were performed by laparoscopy. At inclusion, patients had a median age of 42 years (IQR, 34-53 years) and 89 (78.8\%) were women. There was a higher proportion of women in the GBP group (Table 1). Median TBW was $119 \mathrm{~kg}$ (IQR, 108-135.5 kg) and median BMI was $43.3 \mathrm{~kg} / \mathrm{m}^{2}$ (IQR, 40.6-48.7).

\subsection{Peak anti-Xa levels based on TBW, LBW, IBW or BMI stratum}

Peak plasma levels of anti-Xa activity were determined $4 \mathrm{~h}$ after injection, at steady-state (at least day 2 after thromboprophylaxis initiation). There were no missed doses or delays in dosing that could affect peak levels. Mean and median peak anti-Xa levels were $0.20 \pm 0.10 \mathrm{IU} / \mathrm{mL}$ and $0.19 \mathrm{IU} / \mathrm{mL}$ (IQR, $0.13-0.26 \mathrm{IU} / \mathrm{mL}$ ), respectively. Fifty-nine out of 113 patients (52\%) did not achieve target anti-Xa levels and 1 patient $(0.08 \%)$ had a supraprophylactic level. Patients were further subdivided into increasing tertiles of TBW, LBW and IBW for subgroups analysis (Fig. 1). The percentage of patients who did not achieve the target was significantly higher in the 3rd tertile of LBW (73\% vs $28.9 \%$ and $57.9 \%$ in the 1 st and 2 nd tertiles respectively, $\mathrm{p}=.0005$ ) (Fig. 1 ). The type of surgery did not influence anti-Xa levels.

\subsection{Factors associated with anti-Xa levels}

In univariate analysis, the following patient-related covariates were significantly associated with steady-state peak anti-Xa levels: age $(p=.014)$, gender $(p<0.0001)$, TBW $(p<.0001)$, LBW $(\mathrm{p}<.0001), \operatorname{IBW}(\mathrm{p}<.001), \operatorname{BMI}(\mathrm{p}=.005)$ and eGFR $(\mathrm{p}=.016)$. The strongest correlation was observed with $\operatorname{LBW}(\mathrm{r}=-0.56, \mathrm{p}<.0001)$ (Fig. 2). Construction of ROC curves confirmed that among the four BSD, LBW had the highest sensitivity (73\%) and specificity (69\%) to predict sub-prophylactic plasma anti-Xa levels (cut-off, $55.8 \mathrm{~kg}$; area under the ROC curve, 0.76) (Fig. 3). In multivariate analysis integrating age, gender and type of BS, only LBW ( $\beta$ :$0.47 \pm 0.08, \mathrm{p}<.0001)$ and eGFR $(\beta:-0.19 \pm 0.08, \mathrm{p}=.019)$ remained independent predictors of peak anti-Xa levels $\left(\mathrm{r}^{2}: 0.25 ; \mathrm{p}<.0001\right)$. There was no significant correlation between these two parameters $(\mathrm{r}=0.075, \mathrm{p}=.438)$, which together were able to predict anti-Xa levels according to the following equation: anti-Xa peak level $(\mathrm{IU} / \mathrm{mL})=0.518-[0.00097 \times \mathrm{eGFR}(\mathrm{ml} / \mathrm{min})-0.0037 \times \mathrm{LBW}(\mathrm{kg})]$.

\subsection{Secondary outcomes}

Neither VTE event nor major bleeding occurred during the 3 months follow-up period. One out of 113 patients $(0.9 \%)$ having a sub-prophylactic anti-Xa levels $(0 \mathrm{IU} / \mathrm{ml})$ presented a minor bleeding.

\section{Discussion}

Considering the spectacular rise in BS procedures over the past ten years worldwide [28], there is an urgent need to improve the prevention of their postoperative complications. In the absence of strong evidences or expert consensus statement, thromboprophylaxis remains a therapeutic challenge in severely obese patients undergoing BS, who are at higher risk of both thrombotic and bleeding complications. In a recent nationwide cohort study including more than 110000 patients with a majority of SG, more than $0.5 \%$ of patients experienced VTE during the first 90 post-operative days, despite post hospital discharge chemoprophylaxis in $75 \%$ of cases, suggesting that VTE remains a current concern in BS, particularly in extreme body weights [29]. 
A

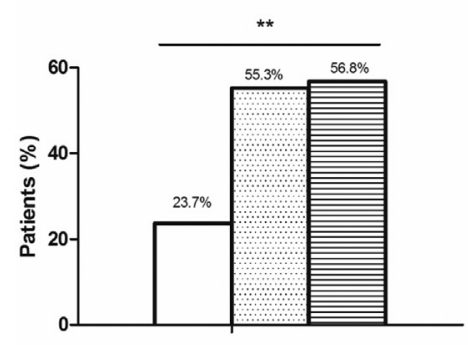

B

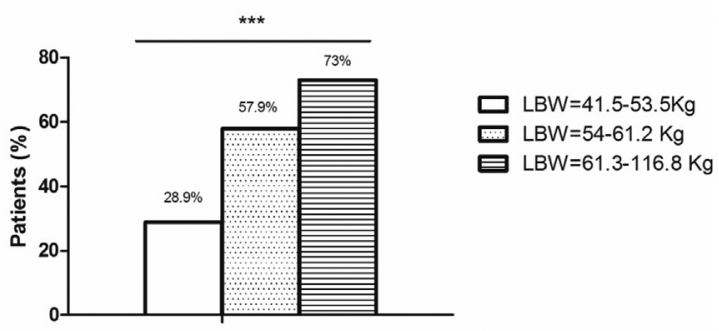

D

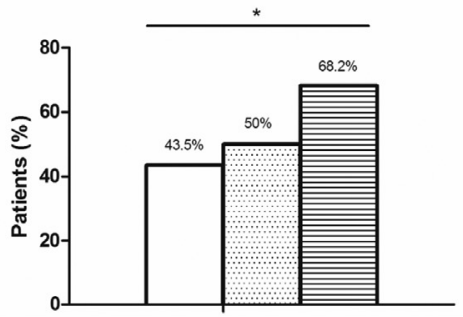

$\square \mathrm{BMl}<40 \mathrm{Kg} / \mathrm{m}^{2}$

... $40 \leq \mathrm{BMl}<50 \mathrm{Kg} / \mathrm{m}^{2}$

回 $\mathrm{BMl} \geq 50 \mathrm{Kg} / \mathrm{m}^{2}$

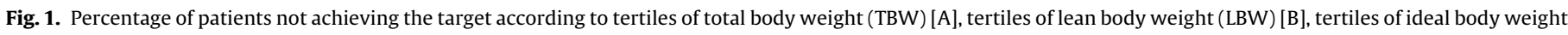
(IBW) [C] or classes of body mass index (BMI) [D].

A

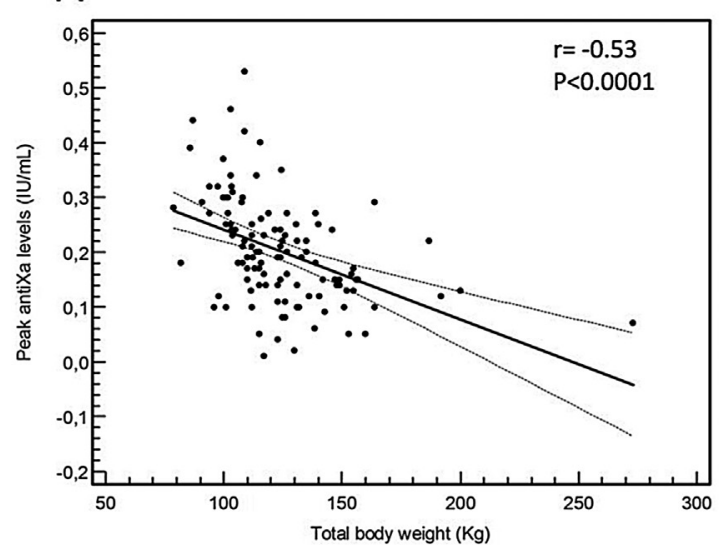

C

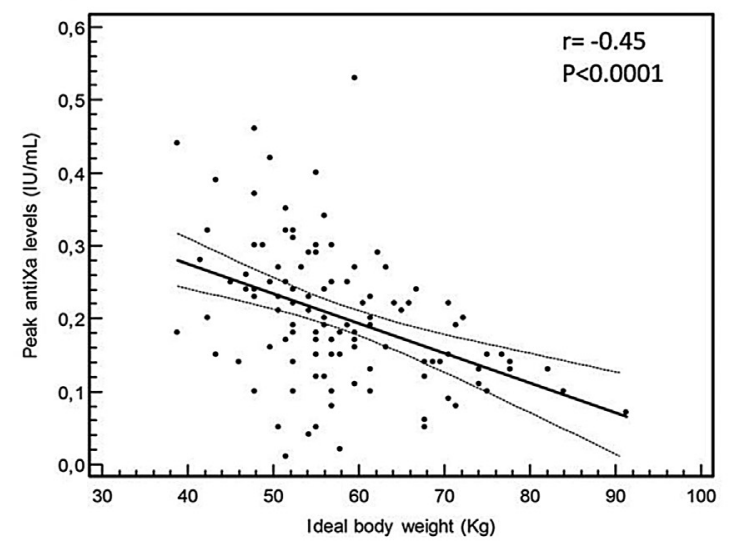

B

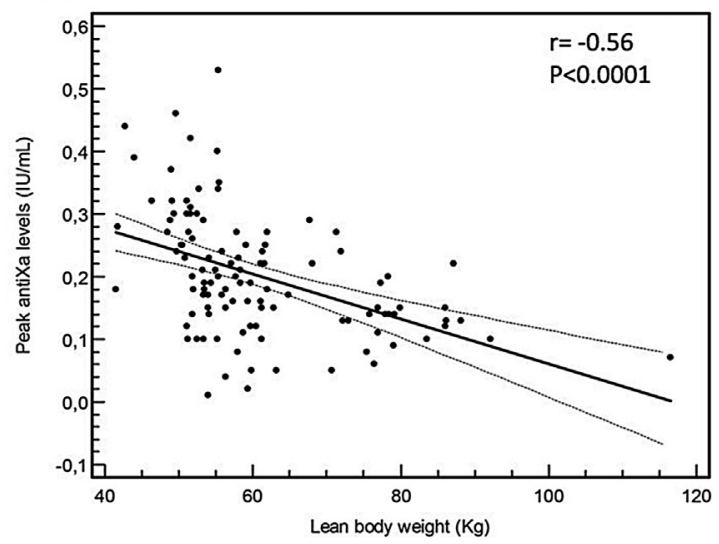

D

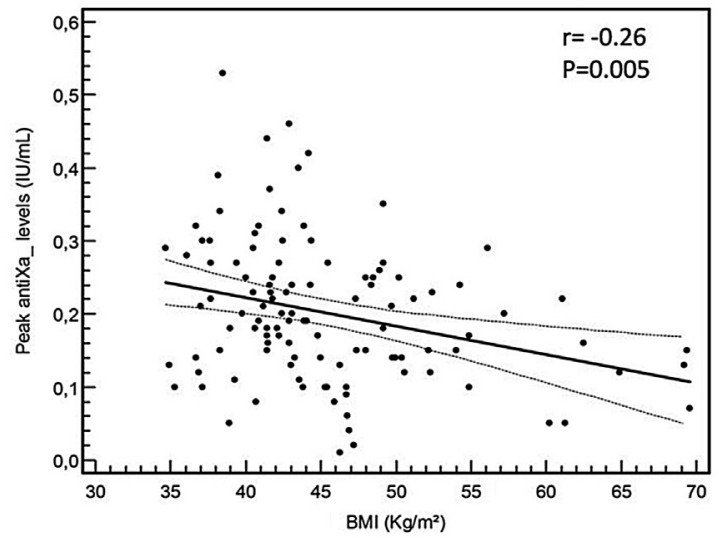

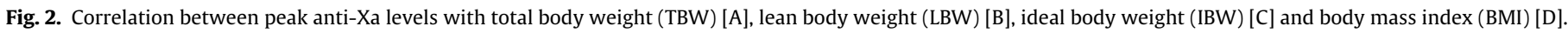
In the figure, $95 \%$ confidence intervals are given for the regression line. 
A

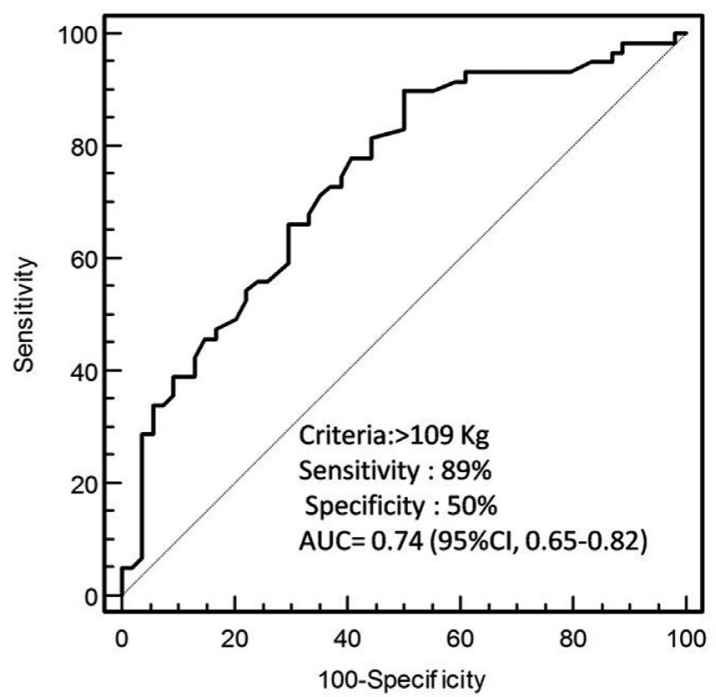

C

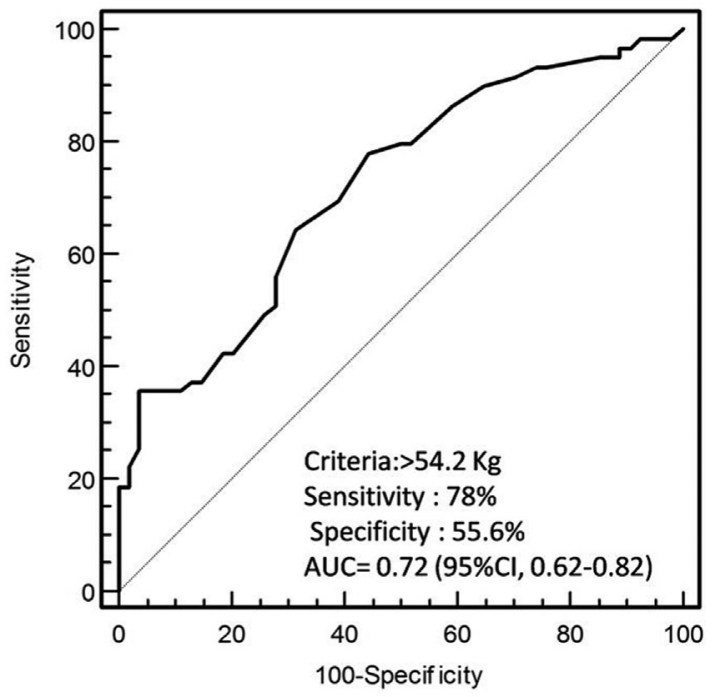

B

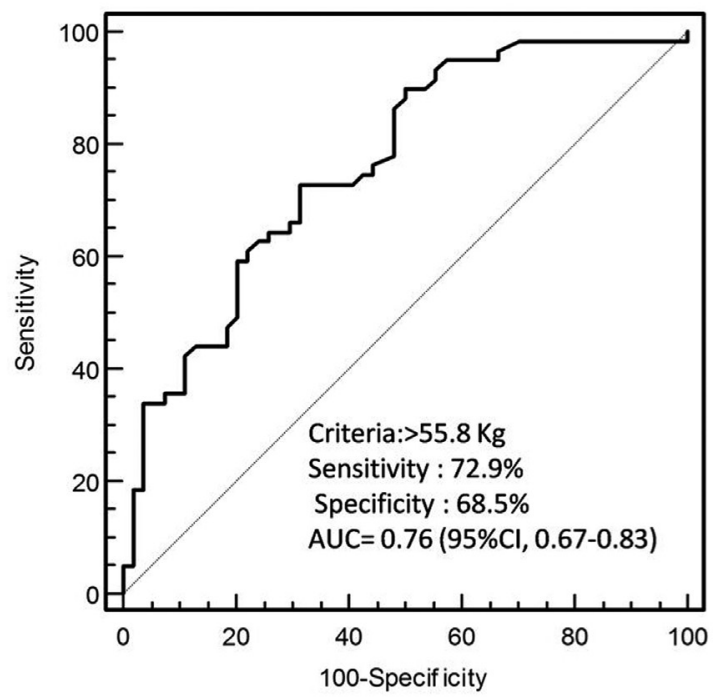

D

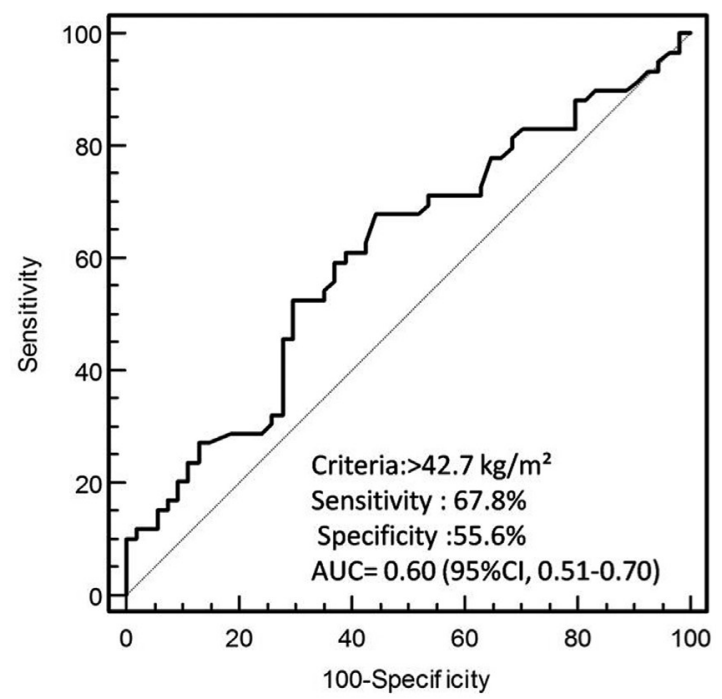

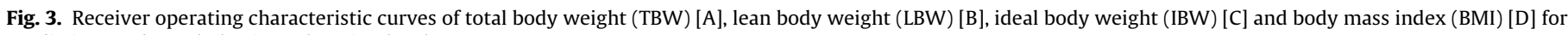
predicting a subprophylactic peak antiXa level.

A growing body of evidence suggests that obese patients would require higher than standard fixed LMWH dosing in order to achieve adequate anticoagulation levels [16,30]. But considering the LMWH pharmacokinetic properties, in severely obese patients, a truly weight-adapted dosing would result in overdosing. The use of a body composition-scale based LMWH dosing algorithm represents thus an opportunity to achieve efficient thromboprophylaxis with an acceptable safety. Therefore, in severely obese patients, LMWH are currently used at higher than standard fixed dosing with a dose capping to prevent overdosing and bleeding complications. A recent meta-analysis of BS patients receiving prophylactic unfractionated heparin and LMWH showed that weight scale-stratified (mostly based on BMI) adjusted dosing tend to be associated with lower VTE rates without excess in bleeding as compared with standard fixed dosing [31]. However, whether LMWH dosing algorithm should be based on BMI or on another BSD in BS patients has never been investigated before.

In the present study, we measured peak anti-Xa levels at steadystate in 113 BS severely obese patients receiving dalteparin 5000 IU twice a day for VTE prevention. We found that only $48 \%$ of patients achieved adequate anti-Xa levels. Our results are consistent with other studies finding a low proportion of patients achieving adequate anti-Xa levels, even when higher than standard fixed dosing of LMWH are used $[11,16]$. We thereafter compared the influence of four BSD (TBW, LBW, IBW, and BMI) on steady-state anti-Xa levels in order to determine which one could be further proposed for an adjusted LMWH dosing algorithm for optimal VTE prevention in severely obese patients. We found that LBW was strongly negatively correlated with anti-Xa levels, and the ROC curves suggested that LBW was the best predictor of subprophylactic anti-Xa levels. A LBW above $55.8 \mathrm{~kg}$ indeed predicted subprophylactic anti-Xa levels with a sensitivity of $72.9 \%$ and a specificity of $68.5 \%$.

We also found a negative correlation observed between antiXa levels and eGFR. LMWH elimination is mostly renal and this negative correlation could be explained by the increased glomerular filtration rate frequently observed in severe obese patients as compared to normal-weight patients. At the opposite, the influence of renal failure on LMWH accumulation has been extensively 
documented. A creatinine clearance of $30 \mathrm{~mL} / \mathrm{min}$ or less has been associated with elevated levels of anti-Xa (and also with an increased risk for major bleeding) in patients treated with prophylactic or therapeutic dose of LMWH. In a previous study of 92 consecutive patients hospitalized in geriatric care units receiving prophylactic doses of $\mathrm{LMWH}$, there was a significant negative correlation between anti-Xa levels and Cockcroft-Gault GFR [32].

Using multivariate analysis, LBW and eGFR remained significantly associated with anti-Xa levels. LBW is a body size descriptor that can be measured with dual-energy X-ray absorptiometry (DXA), or estimated according to the formula of Janmmahasatian et al. [24]. It represents the fat-free mass and a potential useful predictor of the pharmacokinetic behavior of water soluble drugs such as LMWH [33], particularly in obese patients whose fat mass exceeds fat-free mass. Lean body weight correlates with cardiac output and drug clearance and is arguably a used weight scalar to calculate drug doses for obese patients [34].

To the best of our knowledge, two previous small sample size pharmacodynamics studies from Diepstrassen et al. highlighted the interest of LBW in this setting [35,36]. The first one $(n=27)$ showed that LBW correlates with anti-Xa level, better than TBW or BMI and was the only BSD to correlate with the area under the antiXa level-time curve from 0 to $24 \mathrm{~h}\left(\mathrm{AUA}_{0-24 \mathrm{~h}}\right)$ [35]. The second one $(n=35)$ showed that LBW was the most predictive covariate for central volume of distribution [36]. Interestingly, in our study after multivariate analysis, LBW and eGFR were significantly associated with anti-Xa levels, the first one probably reflecting LMWH volume of distribution, and the second one LMWH clearance, but LBW had a greater effect on anti-Xa levels than eGFR as expressed by the standardized coefficients $(\beta$ :- $-0.47 \pm 0.08, p<.0001 v s$. $\beta$ :$0.19 \pm 0.08, \mathrm{p}=.019$ ).

A major limitation of our finding is that achieving anti-Xa peak levels of $0.2-0.4 \mathrm{IU} / \mathrm{mL}$ specified by drug manufacturers has been inconsistently associated with clinical outcomes and venous thromboembolism incidence [37]. It is worth-noting that routinely measuring anti-Xa concentrations in obese patients for the purpose of monitoring the clinical effectiveness of LMWH is not warranted yet. Further understanding of prophylactic anti-Xa peak levels is hence necessary before developing dosing algorithms.

In conclusion, LBW and eGFR are the main determinants of antiXa level in BS obese patients receiving LMWH. This finding should be considered when initiating thromboprophylaxis in this specific population. Indeed, there are a lot of obesity phenotypes with different adiposity and fat free mass distribution that warrant going beyond BMI in LMWH dose adjustment. Considering that LMWH proper dosing is critical in this setting, the efficacy of a LBW-scale based dosing algorithm for optimal VTE prevention deserves further prospective randomized trials.

\section{Ethical approval}

All procedures performed in studies involving human participants were in accordance with the ethical standards of the institutional and/or national research committee and with the 1964 Helsinki declaration and its later amendments or comparable ethical standards.

\section{Informed consent}

Informed consent was obtained from all individual participants included in the study.

\section{Conflict of Interest}

The authors declare that they have no conflict of interest.

\section{References}

[1] P.D. Stein, A. Beemath, R.E. Olson, Obesity as a risk factor in venous thromboembolism, Am. J. Med. 118 (2005) 978-980.

[2] A.T. Rocha, A.G. de Vasconcellos, E.R. da Luz Neto, D.M.A. Araújo, E.S. Alves, A.A. Lopes, Risk of venous thromboembolism and efficacy of thromboprophylaxis in hospitalized obese medical patients and in obese patients undergoing bariatric surgery, Obes. Surg. 16 (2006) 1645-1655.

[3] M.H. Jamal, R. Corcelles, H. Shimizu, M. Kroh, F.M. Safdie, R. Rosenthal, et al., Thromboembolic events in bariatric surgery: a large multi-institutional referral center experience, Surg. Endosc. 29 (2015) 376-380.

[4] J.A. Sapala, M.H. Wood, M.P. Schuhknecht, M.A. Sapala, Fatal pulmonary embolism after bariatric operations for morbid obesity: a 24-year retrospective analysis, Obes. Surg. 13 (2003) 819-825.

[5] B.J. Carmody, H.J. Sugerman, J.M. Kellum, M.K. Jamal, J.M. Johnson, A.M. Carbonell, et al., Pulmonary embolism complicating bariatric surgery: detailed analysis of a single institution's 24-year experience, J. Am. Coll. Surg. 203 (2006) 831-837.

[6] P.D. Stein, F. Matta, Pulmonary embolism and deep venous thrombosis following bariatric surgery, Obes. Surg. 23 (2013) 663-668.

[7] M.J. Hanley, D.R. Abernethy, D.J. Greenblatt, Effect of obesity on the pharmacokinetics of drugs in humans, Clin. Pharmacokinet. 49 (2010) 71-87.

[8] A.J. Mayr, M. Dünser, S. Jochberger, D. Fries, A. Klingler, M. Joannidis, et al. Antifactor Xa activity in intensive care patients receiving thromboembolic prophylaxis with standard doses of enoxaparin, Thromb. Res. 105 (2002) 201-204.

[9] S.G. Frederiksen, J.L. Hedenbro, L. Norgren, Enoxaparin effect depends on body-weight and current doses may be inadequate in obese patients, $\mathrm{Br}$. J. Surg. 90 (2003) 547-548

[10] A.L. Freeman, R.C. Pendleton, M.T. Rondina, Prevention of venous thromboembolism in obesity, Expert Rev. Cardiovasc. Ther. 8 (2010) $1711-1721$

[11] B.O. Rowan, D.A. Kuhl, M.D. Lee, D.S. Tichansky, A.K. Madan, Anti-Xa levels in bariatric surgery patients receiving prophylactic enoxaparin, Obes. Surg. 18 (2008) 162-166.

[12] E.P. Simone, A.K. Madan, D.S. Tichansky, D.A. Kuhl, M.D. Lee, Comparison of two low-molecular-weight heparin dosing regimens for patients undergoing laparoscopic bariatric surgery, Surg. Endosc. 22 (2008) 2392-2395.

[13] M.J. Borkgren-Okonek, R.W. Hart, J.E. Pantano, P.C. Rantis, P.J. Guske, J.M. Kane, et al., Enoxaparin thromboprophylaxis in gastric bypass patients: extended duration, dose stratification, and antifactor Xa activity, Surg. Obes. Relat. Dis. 4 (2008) 625-631.

[14] D. Imberti, C. Legnani, E. Baldini, M. Cini, A. Nicolini, M. Guerra, et al., Pharmacodynamics of low molecular weight heparin in patients undergoing bariatric surgery: a prospective, randomised study comparing two doses of parnaparin (BAFLUX study), Thromb. Res. 124 (2009) 667-671.

[15] F. Celik, A.D.R. Huitema, J.H. Hooijberg, A.W.J.M. van de Laar, D.P.M. Brandjes, V.E.A. Gerdes, Fixed-dose enoxaparin after bariatric surgery: the influence of body weight on peak anti-Xa levels, Obes. Surg. 25 (2015) 628-634.

[16] M.A. Bartlett, K.F. Mauck, P.R. Daniels, Prevention of venous thromboembolism in patients undergoing bariatric surgery, Vasc. Health Risk Manag. 11 (2015) 461-477.

[17] J.I. Mechanick, A. Youdim, D.B. Jones, W.T. Garvey, D.L. Hurley, M.M. McMahon, et al., Clinical practice guidelines for the perioperative nutritional, metabolic, and nonsurgical support of the bariatric surgery patient-2013 update: cosponsored by American Association of Clinical Endocrinologists, The Obesity Society, and American Society for Metabolic \& Bariatric Surgery, Obesity (Silver Spring Md) 21 (Suppl. 1) (2013) S1-27.

[18] American Society for Metabolic Bariatric Surgery Clinical Issues Committee, ASMBS updated position statement on prophylactic measures to reduce the risk of venous thromboembolism in bariatric surgery patients, Surg. Obes. Relat. Dis. 9 (2013) 493-497.

[19] M.K. Gould, D.A. Garcia, S.M. Wren, P.J. Karanicolas, J.I. Arcelus, J.A. Heit, et al., Prevention of VTE in nonorthopedic surgical patients: antithrombotic therapy and prevention of thrombosis, 9th ed: american college of chest physicians evidence-based clinical practice guidelines, Chest 141 (2012) e227S-e277S.

[20] M.T. Rondina, M. Wheeler, G.M. Rodgers, L. Draper, R.C. Pendleton, Weight-based dosing of enoxaparin for VTE prophylaxis in morbidly obese, medically-Ill patients, Thromb. Res. 125 (2010) 220-223.

[21] K. Singh, E.R. Podolsky, S. Um, S. Saba, I. Saeed, L. Aggarwal, et al., Evaluating the safety and efficacy of BMI-based preoperative administration of low-molecular-weight heparin in morbidly obese patients undergoing Roux-en-Y gastric bypass surgery, Obes. Surg. 22 (2012) 47-51.

[22] C.-M. Samama, B. Gafsou, T. Jeandel, S. Laporte, A. Steib, E. Marret, et al., French society of anaesthesia and intensive care. Guidelines on perioperative venous thromboembolism prophylaxis. Update 2011. short text, Ann. Fr. Anesth. Reanim. 30 (2011) 947-951.

[23] A.M. Gotto, E.L. Bierman, W.E. Connor, C.H. Ford, I.D. Frantz, C.J. Glueck, et al., Recommendations for treatment of hyperlipidemia in adults: a joint statement of the Nutrition Committee and the Council on Arteriocslerosis, Circulation 69 (1984) 1065A-1090A.

[24] S. Janmahasatian, S.B. Duffull, S. Ash, L.C. Ward, N.M. Byrne, B. Green, Quantification of lean bodyweight, Clin. Pharmacokinet. 44 (2005) 1051-1065. 
[25] M.P. Pai, F.P. Paloucek, The origin of the ideal body weight equations, Ann. Pharmacother. 34 (2000) 1066-1069.

[26] M.Y. Wei, S.M. Ward, The anti-factor xa range for low molecular weight heparin thromboprophylaxis, Hematol. Rep. 7 (2015) 5844

[27] S. Schulman, U. Angerås, D. Bergqvist, B. Eriksson, M.R. Lassen, W. Fisher, et al., Definition of major bleeding in clinical investigations of antihemostatic medicinal products in surgical patients, J. Thromb. Haemost. JTH 8 (2010) 202-204.

[28] L. Angrisani, A. Santonicola, P. Iovino, G. Formisano, H. Buchwald, N. Scopinaro, Bariatric surgery worldwide 2013, Obes. Surg. 25 (2015) $1822-1832$.

[29] J. Thereaux, T. Lesuffleur, S. Czernichow, A. Basdevant, S. Msika, D. Nocca, et al., To what extent does posthospital discharge chemoprophylaxis prevent venous thromboembolism after bariatric surgery?: Results from a nationwide cohort of more than 110,000 patients, Ann. Surg. (2017).

[30] S.G. Parker, E.R. McGlone, W.R. Knight, P. Sufi, O.A. Khan, Enoxaparin venous thromboembolism prophylaxis in bariatric surgery: a best evidence topic, Int J. Surg. Lond. Engl. 23 (2015) 52-56.

[31] R. Ikesaka, A. Delluc, G. Le Gal, M. Carrier, Efficacy and safety of weight-adjusted heparin prophylaxis for the prevention of acute venous thromboembolism among obese patients undergoing bariatric surgery: a systematic review and meta-analysis, Thromb. Res. 133 (2014) 682-687.
[32] B. Dufour, M. Toussaint-Hacquard, A. Kearney-Schwartz, M.D.P. Manckoundia, M.C. Laurain, L. Joly, et al., Glomerular filtration rate estimated by Cockcroft-Gault formula better predicts anti-Xa levels than modification of the diet in renal disease equation in older patients with prophylactic enoxaparin, J. Nutr. Health Aging 16 (2012) 647-652.

[33] B. Green, S.B. Duffull, What is the best size descriptor to use for pharmacokinetic studies in the obese? Br. J. Clin. Pharmacol. 58 (2004) $119-133$.

[34] J.H.P. Friesen, Lean-scaled weight: a proposed weight scalar to calculate drug doses for obese patients, Can. J. Anaesth. 60 (2013) 214-215.

[35] J. Diepstraten, C.M. Hackeng, S. van Kralingen, J. Zapletal, E.P.A. van Dongen, R.J. Wiezer, et al., Anti-Xa levels $4 \mathrm{~h}$ after subcutaneous administration of 5,700 IU nadroparin strongly correlate with lean body weight in morbidly obese patients, Obes. Surg. (2012).

[36] J. Diepstraten, E.J.H. Janssen, C.M. Hackeng, E.P.A. van Dongen, R.J. Wiezer, B. van Ramshorst, et al., Population pharmacodynamic model for low molecular weight heparin nadroparin in morbidly obese and non-obese patients using anti-Xa levels as endpoint, Eur. J. Clin. Pharmacol. 71 (2015) 25-34.

[37] G. Egan, M.H.H. Ensom, Measuring anti-factor xa activity to monitor low-molecular-weight heparin in obesity: a critical review, Can. J. Hosp. Pharm. 68 (2015) 33-47. 